\title{
Design and implementation proposed system for encryption true images
}

\author{
Asst. Prof. Dr.Baheja K.Shukur ${ }^{1}$, Ala aldeen abbas Abdulhassan \\ ${ }^{1,2}$ Computer Technology/network department, Babylon University, Iraq
}

\begin{abstract}
Image encryption method prepared information unreadable. Therefore, no hacker or eavesdropper, including server administrators and others, have access to original message or any other type of transmitted information through public networks such as internet.

This paper presented a secure encryption method for true image encryption, which gets the benefits of both methods (symmetric and asymmetric encryption methods); a hybrid technique is usually used. In this technique, asymmetric encryption (RSA) is used to encrypt the security message the resulting cipher text is converted to binary form then symmetric encryption designed to encrypt the resulted cipher bits by making XOR operation with it. The design of symmetric key provides good confusion and diffusion properties that ensures high security. The easiest way to do this is through the design of the strong threshold linear feedback shift register, where the R,G,B bytes is ciphered with a single distinct bit generated from making XOR operation between key generator and resulting binary cipher bits, which made the ciphers are more complex, the key is said to be well designed and its size provides an upper bound of an algorithm's cryptographic strength, which consist of four shift registers the length them are 12,10,7,5 respectively, three of them are linear and the other are nonlinear,also the design of the linear feedback function very strong, which provided maximum length period. The opposite operation is performed to reconstructed the original image and the original secure message in addition to that different measured have been used to explain the range of the difference between the regional and cipher images and to show the power of the encryption methods, such as histogram, Calibrated area, Mean, Standard deviation, Median, Calibrated center of mass, Calibrated perimeter, and Calibrated ferret diameter.
\end{abstract}

Keyword: linear feedback shift register, RSA, symmetric cipher, asymmetric cipher.

\section{INTRODUCTION}

Information security is a description of each process that prevent unauthorized access or use of the data transmitted, that access or use may be takes the form of distortion, use, disclosure, modification, or disruption. The main use of cryptography is to provide the following criteria such as the confidentiality; integrity and availability of the information ignoring data form for protecting the interconnected and share the common services.

Encryption changes the shape or location information so that does not allow unauthorized access or use of content. The strength of the encryption and decryption code system depends on the length and strength of the encryption key to prevent unauthorized person from access to the content of the text [1].

In the encryption and decryption process of a symmetric cipher both, must use the same key. Thus any messages can be decrypted the encryption key must be shared between the two persons. For this reason symmetric systems are known as shared secret systems or private key systems. Compared to asymmetric ciphers the Symmetric ciphers are significantly faster than asymmetric ciphers, but the requirements for key exchange make them difficult to use.

In an asymmetric cipher, there are two kinds of functions and two different keys. As a result each person has two keys. One of them is, the public key, is shared publicly [2], while the other is the private key, should never be shared with anyone. The recipient's public key using to encrypt the message when you send a message using asymmetric cryptography. The recipient then decrypts the message using his private key. For this reason the system is called asymmetric.

In this work the security massage for long length encrypted using RSA system, the resulted cipher text converted to the binary form then making XOR operation with the sequences bits resulted from threshold key generator for long 12,10,7,5 bits and strong feedback function.

.Because the security of image data from unauthorized uses is important therefore; images are widely used in different-different processes. To protect confidential image data from unauthorized access so many image encryption techniques are available to be used [3].

For suitable access to and sharing a large number of digital images now transmitted over Internet and wireless networks through the developments of multimedia and networks technologies, [4], therefore the content of the Multimedia must be protected from an authorized by using method or a set of methods of security, which 
based on cryptography and they allow each communication security, or security against piracy or both. The security of this multimedia can be accomplished by using hybrid methods between the symmetric and asymmetric algorithm and the (R, G, and $\mathrm{B}$ ) bytes of the images after converting them to the binary value exploiting the properties of the XOR operation between the results of the encryption and bytes of image. The using of these methods for encryption to this multimedia attempt to transform an image to another one that is hard to recognize. To recovers the original image from the encrypted one image decryption used [5].

In addition to that two main parts involves in stream cipher which are they a key generator, and a mixing function. The first one is a mixing function which is usually just an XOR function; the second one is a key stream generator which is the main unit in stream cipher encryption method. Stream ciphers encrypt plaintext bits individually. Each bit $x_{i}$ is encrypted by adding a secret key stream bit $s_{i}$ modulo 2 .

i.e., $x_{i}, y_{i}, s_{\mathrm{i}} \in\{0,1\}$.

Encryption: $y_{i}=e_{s i}(x i) \equiv x_{i}+s_{i} \bmod 2$.

Decryption: $x_{i}=d_{s i}\left(y_{i}\right) \equiv y_{i}+s_{i} \bmod 2$.

\section{THE STRUCTURE OF THE PROPOSED SYSTEM}

The structure of the proposal system can be shown in the figure (1) as shown below:

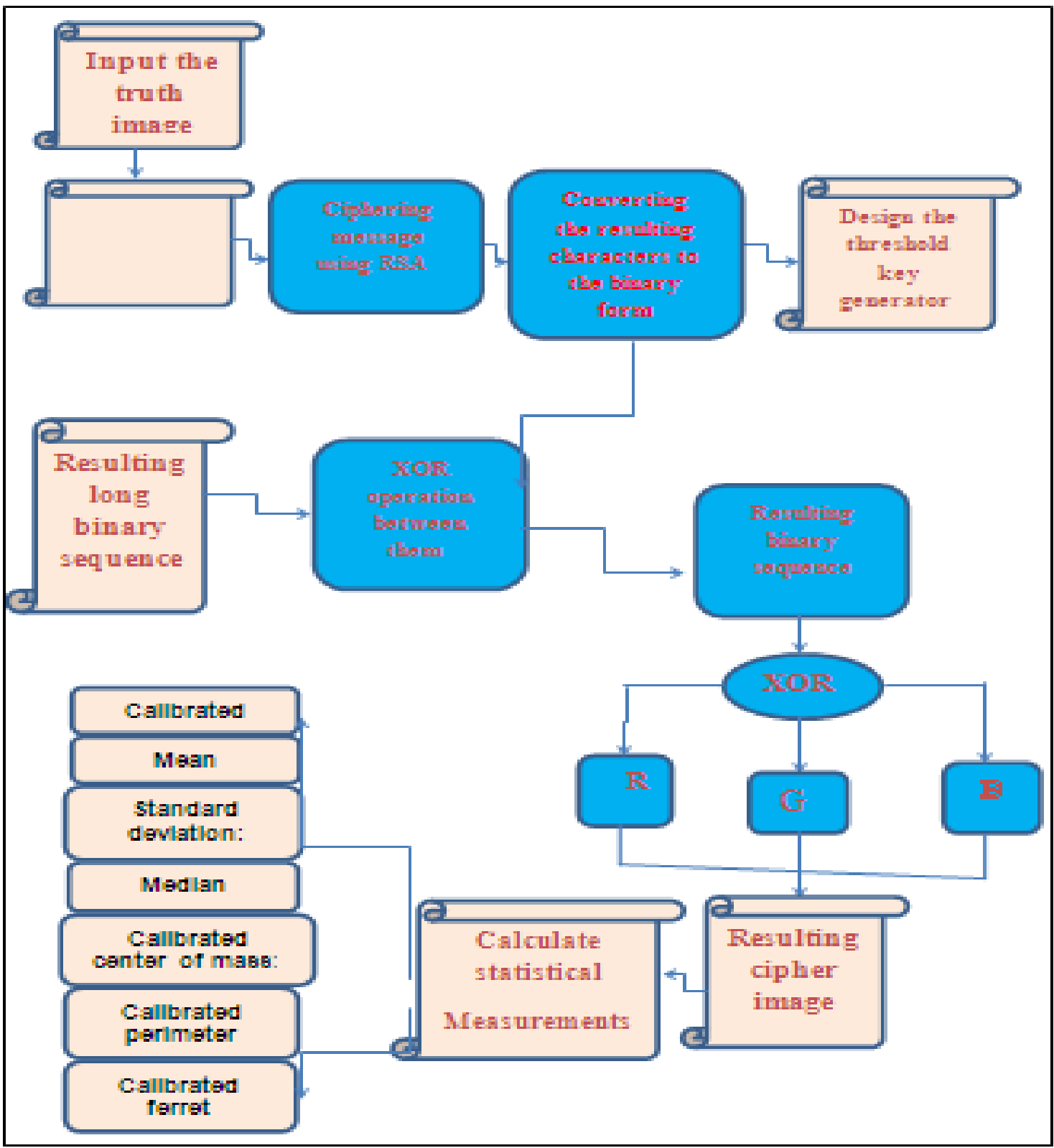

Figure (1) the structure of the suggested system 


\section{III.1RSA Algorithm}

\section{III.THE ALGORITHMS USED IN THIS SYSTEM} are different [6].

Public-key cryptography called asymmetric cryptography, where the keys used to encrypt and decrypt

One type of the public key system is RSA which involves a public and private key. Anyone who wants to be sender need to publish an encryption key, which is known as the public key, but anyone who want to be receiver needs a unique decryption key which is known as private key [7]. Each letter in the message is converted to a decimal number by ASCII code, and encrypted by using the public key.

This algorithm is the most widely public-key encryption algorithm used, that provides confidentially and digital signature.

The keys for the RSA algorithm are generated in the following way [8].

Each entity A creates public key and corresponding private by doing the following:

$\square$ Generate three distinct large random prime numbers $\mathrm{p}, \mathrm{q}$, and e

Compute $n=p * q$

$\square$ A's public key (e, n) // to be published

$\square$ Who is capable of computing $\mathrm{d}$ ?

$$
\begin{aligned}
& d=\frac{\operatorname{gcd}(\Phi(n)) * \Phi(n)+1}{e} \\
& \square(\mathrm{n})=(\mathrm{p}-1)(\mathrm{q}-1)
\end{aligned}
$$

To verification d: we must [ $\left.\mathrm{e}^{*} \mathrm{~d} \bmod \Phi(\mathrm{n})=1\right]$

A's private key :( $d, n) / /$ to be kept secretly by A

$e$ is released as the public key exponent [9].

Encryption: $C=m^{e}(\bmod n)$, Decryption: $m=c^{d}(\bmod n)$

The decoder can recover $\mathrm{m}$ from by using her private key exponent $\mathrm{d}$ by the following computation:

$m \equiv \mathrm{c}^{\mathrm{d}}(\bmod \mathrm{n})$, Given $m$., the decoder can recover the original message $w$ here

$m$ : The plain-text message, $c$ : the encrypted message expressed as an integer number.

$n$ : the product of two randomly selected, large primes $p$ and $q$.

$e:$ a large, random integer relatively prime to $(p-1) *(q-1)$.

$d$ : the multiplicative inverse of $e$.

\section{III.2 The suggested threshold key generator}

This generator is one type of the stream cipher ,in this work this key consist of four linear feedback shift registers of length 12,10,7,5, three of them are linear and the other are non-linear, where each one have maximum length period according to the primitive feedback function used.

The dynamic of this generator are:

If more than half the output 1 , then the output of the generator 1 Otherwise 0 .

The structure of this generator can be shown in figure (2): 

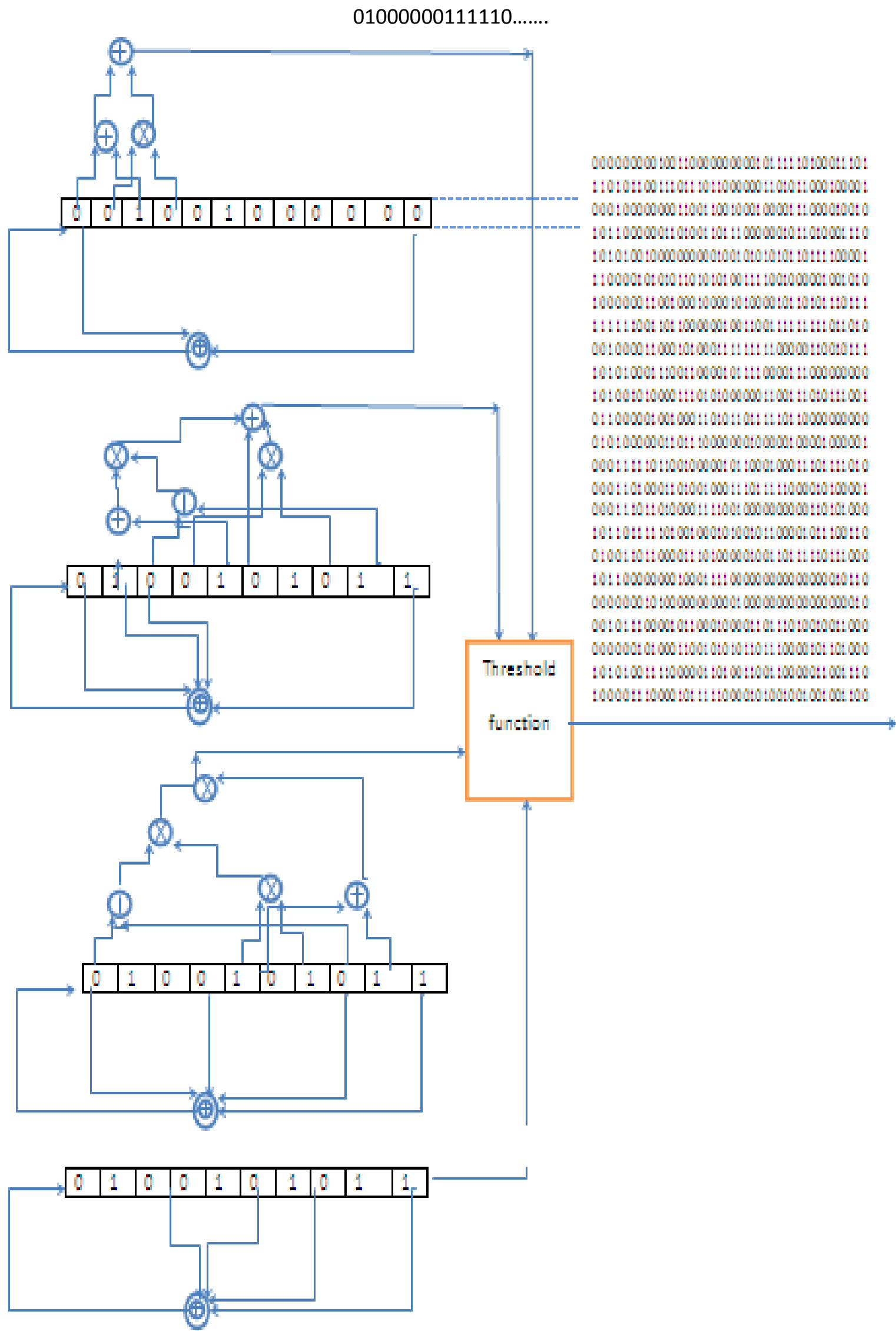

Figure (2) the suggested structure of the key generator 
III.3 The plain and cipher text used in this system

For example the secure message supposed to be protected from the malicious passed in all steps before encrypted with the image bytes as below in table (1):

Table (1) contain the plain and cipher text and suggested key generator used in the encryption processes

\begin{tabular}{|c|c|}
\hline Plain text & Cipher text by RSA \\
\hline $\begin{array}{l}\text { A common foundation for information } \\
\text { security will provide the } \\
\text { Intelligence, Defense, and Civil sectors } \\
\text { of the federal government and } \\
\text { their contractors, more uniform and } \\
\text { consistent ways to manage the risk to } \\
\text { organizational operations and assets, } \\
\text { individuals, other organizations, and } \\
\text { the Nation that results from the operation } \\
\text { and use of information systems. }\end{array}$ & 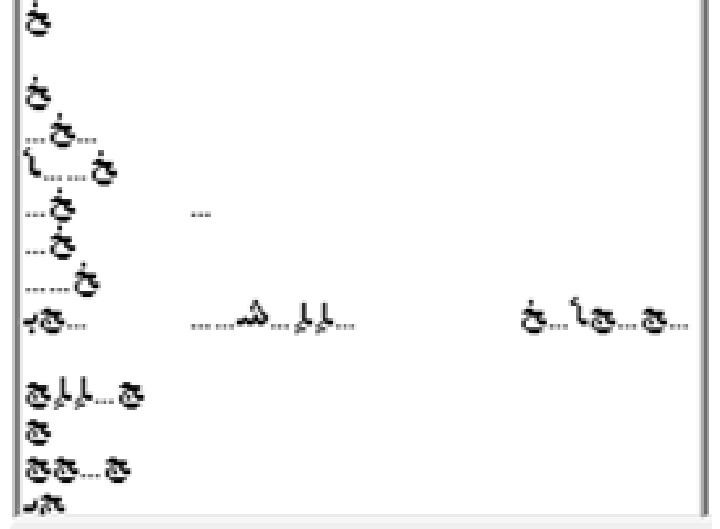 \\
\hline \multicolumn{2}{|c|}{ The plain text and resulted cipher text from RSA system } \\
\hline Cipher text in binery Binery Key $B$ & tream cipher Cipher text X-OR Binery Key \\
\hline 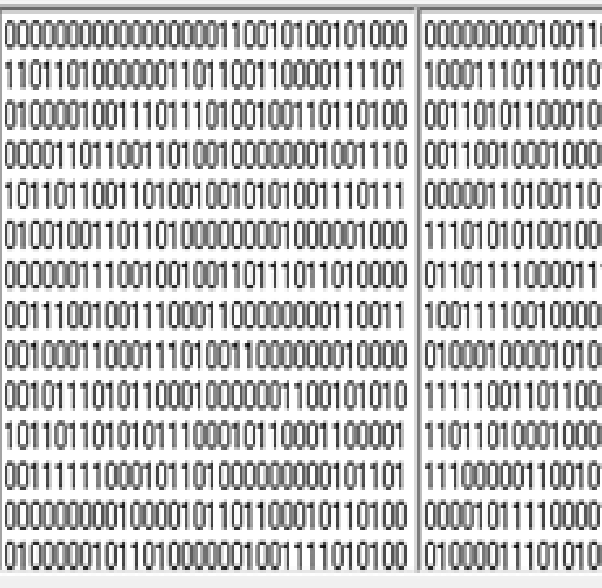 & 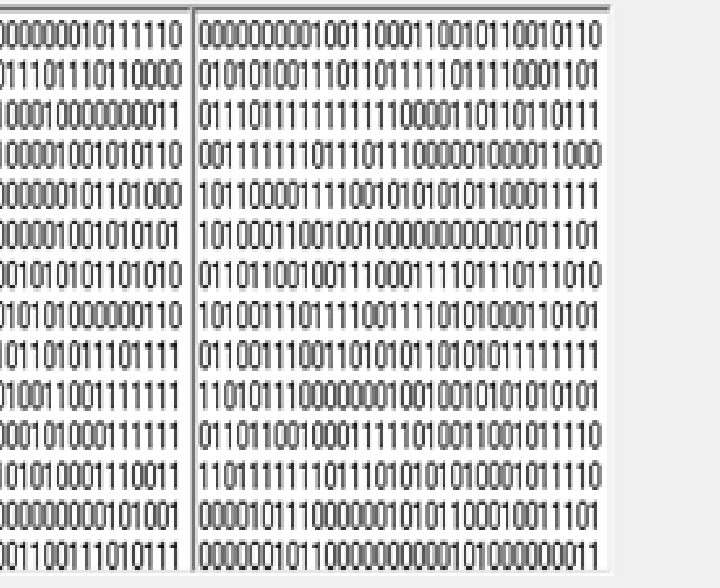 \\
\hline
\end{tabular}

III. THE SECURITY OF THE PROPOSED SYSTEM

Below table (2) show the implementation of the proposed system using hybrid methods for text security and encrypted different images which reflect the security of this system.

Table (2) the implementation of the security system

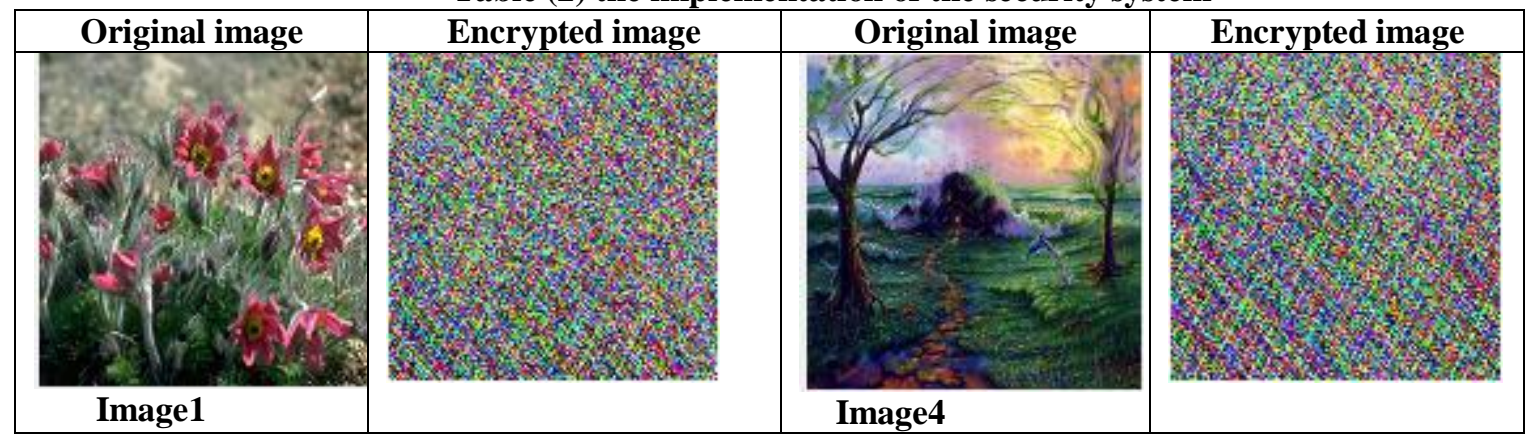



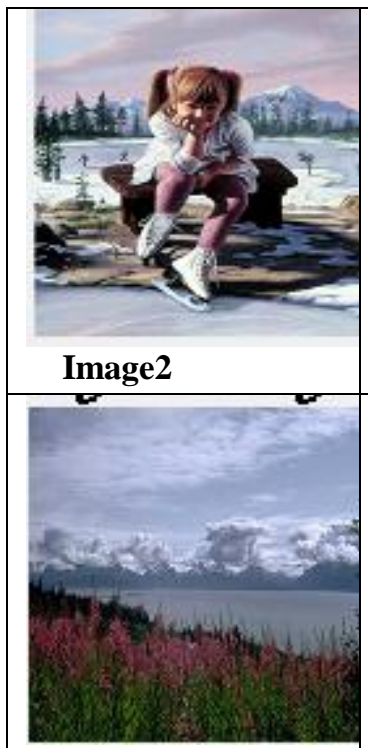

Image3
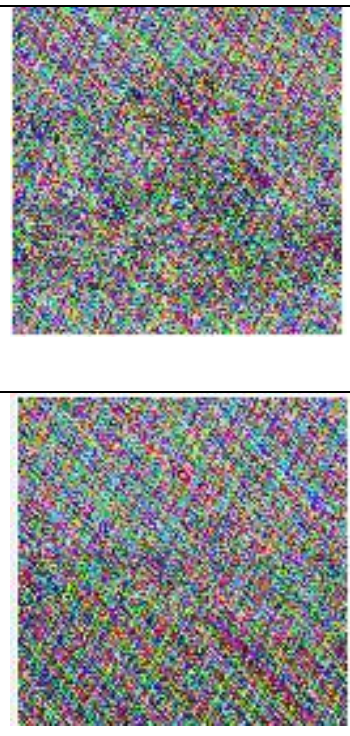

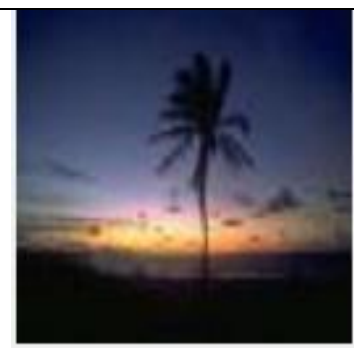

Image5

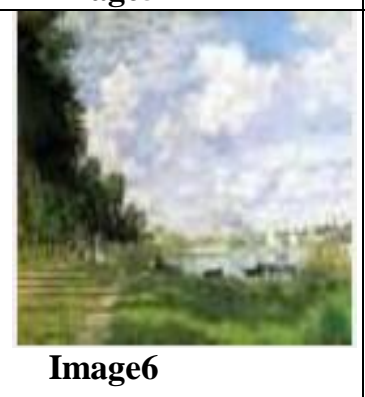

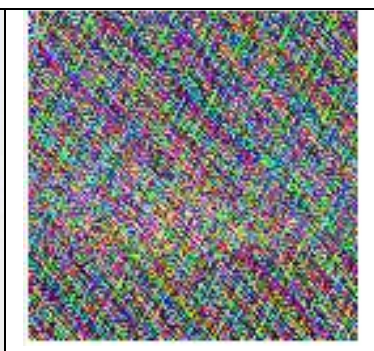

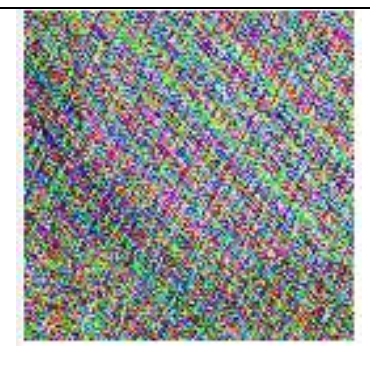

IV.

THE HISTOGRAM OF THE ORIGINAL AND ENCRYPTED IMAGES

The histogram of the original and encrypted images used to show the difference between them, which reflects the strength of the encryption methods usedin this system, that combining the behavior for the symmetric and a symmetric encryption methods using with bytes of these images for different types of image. As shown in table (3) below.

Table (3) the histogram of the original and encryption images
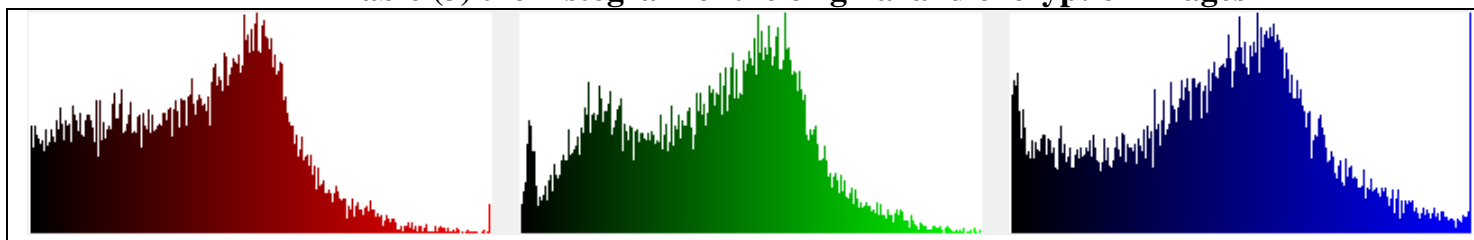

The histogram of the original image1

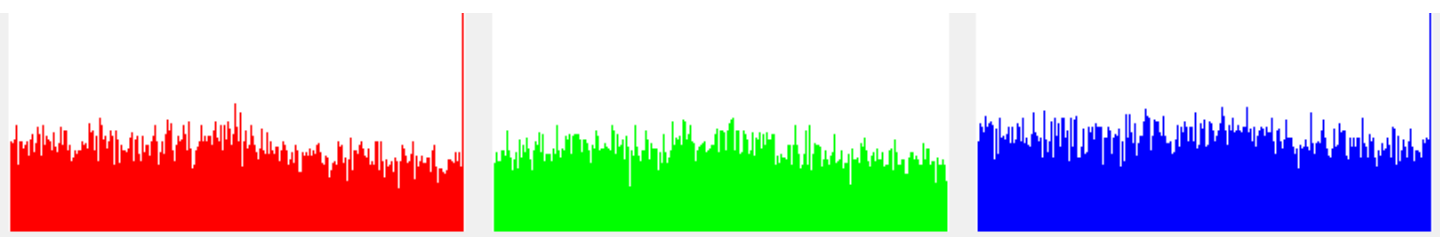

The histogram of the encrypted image1

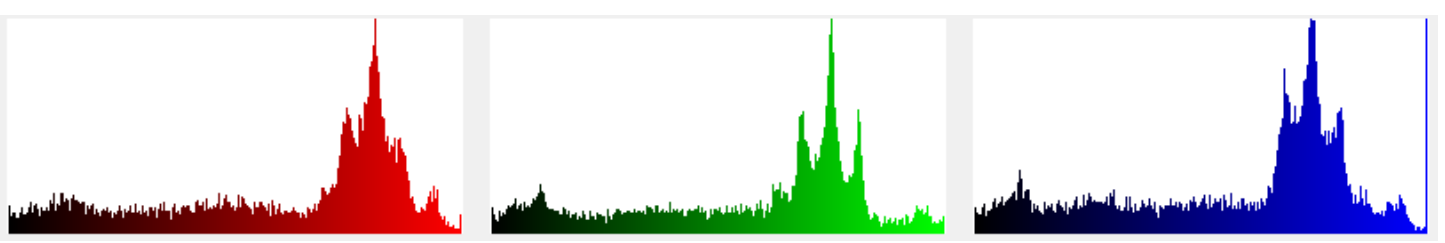

The histogram of the original image 2 

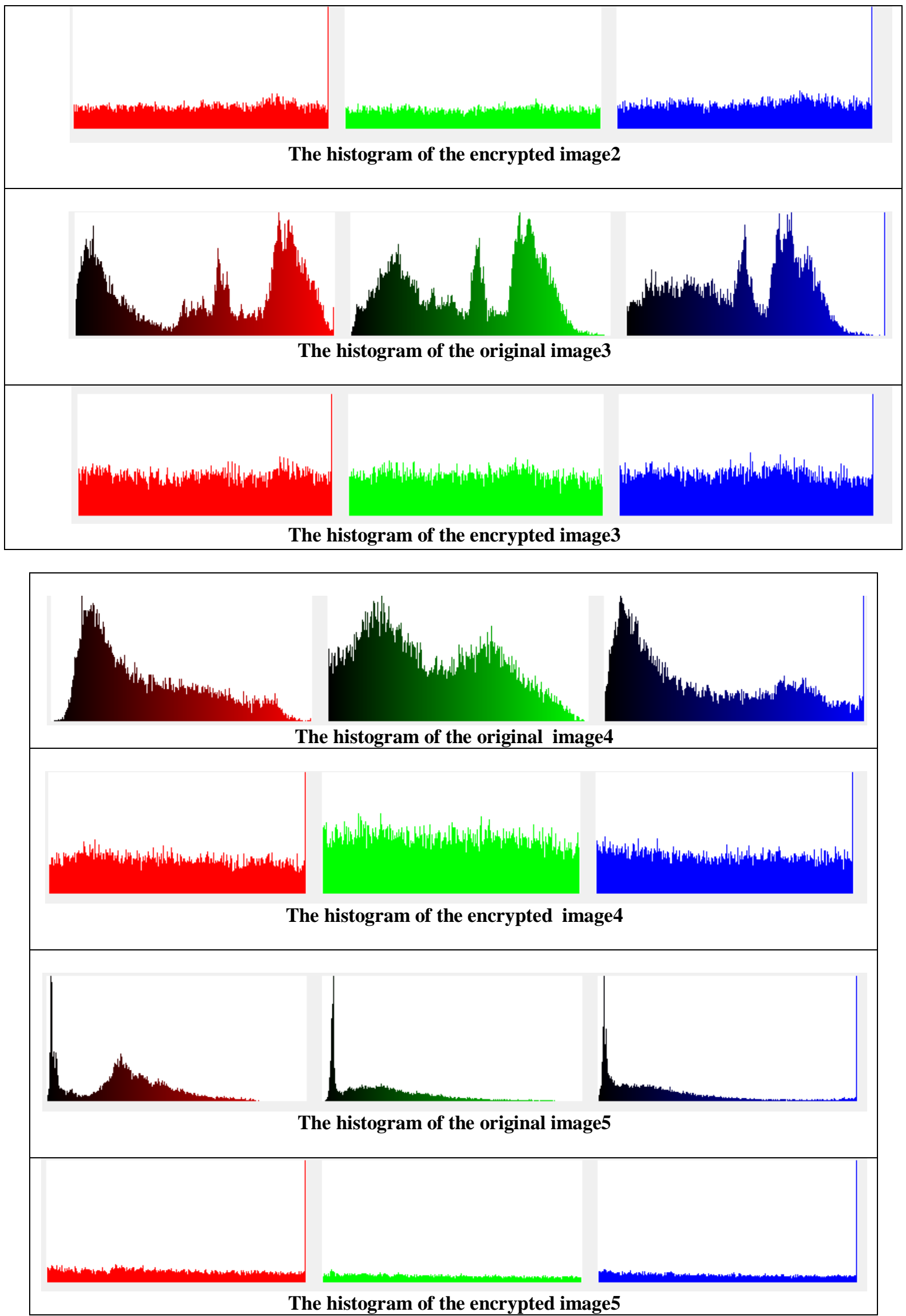


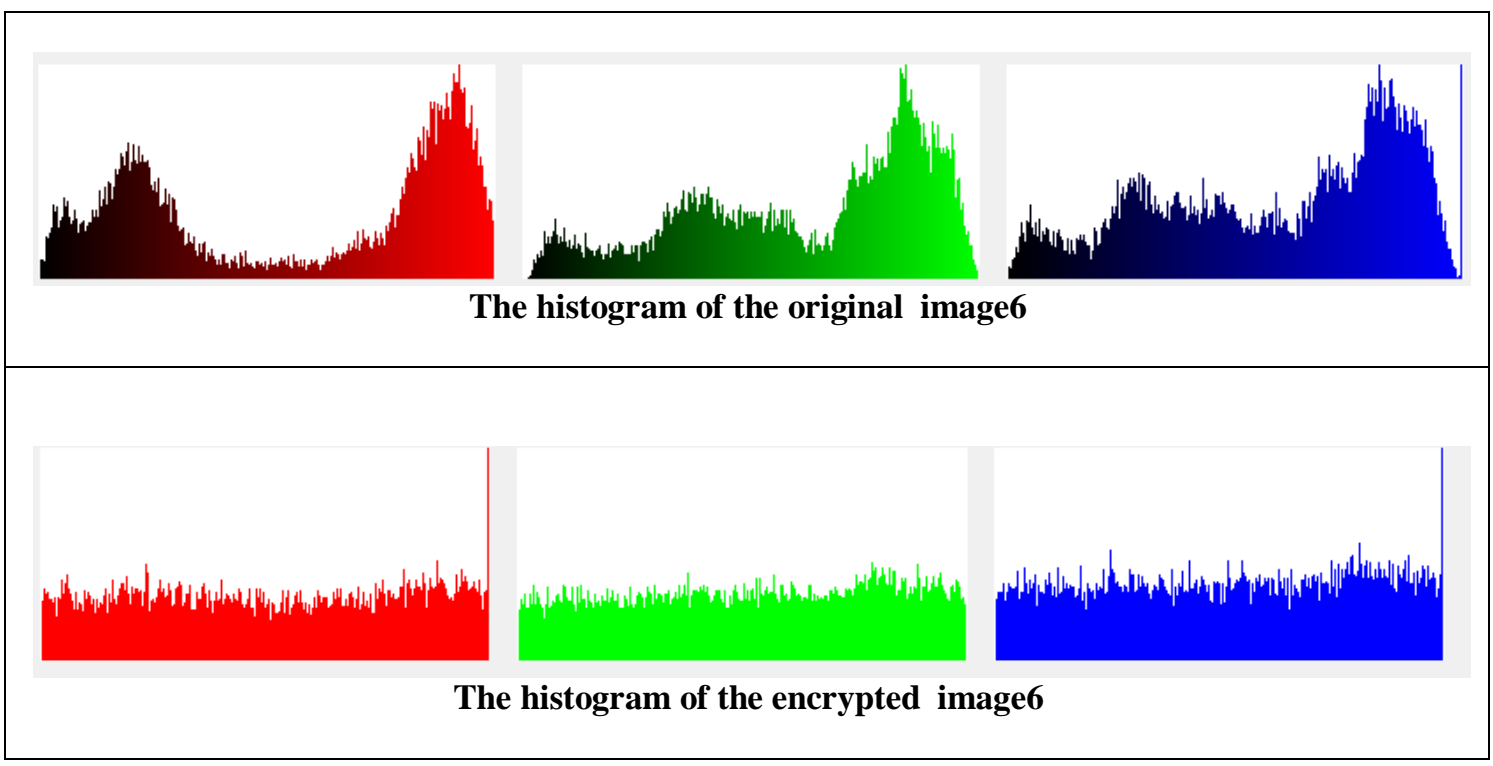

\section{THE IMPLEMENTATION OF THE PROPOSED SYSTEM AND RESULTS}

This system is tested for different types of image, figure (3) show the this system, which implemented for image1, That's where the RSA method used to encryption chosen plain-text, which in turn converts to binary bits These bits combine with bits resulting from the proposed generator key and then encrypts each byte of the image with the bytes of the resulting binaries of encryption.

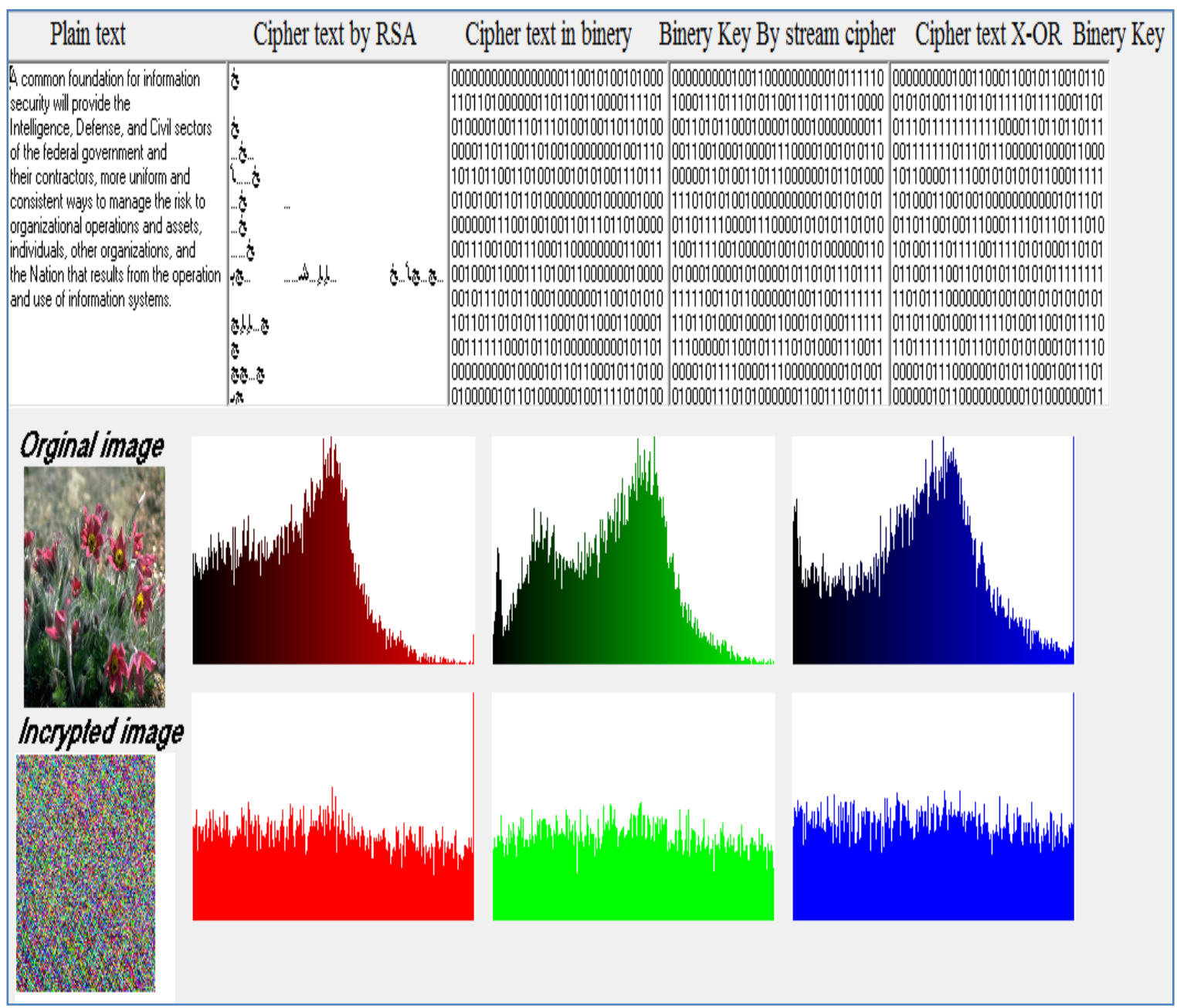

Figure (3) show the implemented of proposed system for image1 
VI.

THE STATISTICAL MEASUREMENTS USED

Table (4) show the statistical measurements for encrypted image1 and original image1

\begin{tabular}{|c|c|c|c|}
\hline measurements & encrypted image 2 & measurements & original image 2 \\
\hline Calibrated area: & 3.160 sq. in & Calibrated area: & 0.182 sq. in \\
\hline Mean: & & Mean: & \\
\hline - Luminosity & 131.163 & - Luminosity & 143.17 \\
\hline - Red & 131.405 & - Red & 144.035 \\
\hline - Green & 131.593 & - Green & 142.055 \\
\hline - Blue & 132.636 & - Blue & 151.266 \\
\hline Standard deviation: & & $\begin{array}{l}\text { Standard } \\
\text { deviation: }\end{array}$ & \\
\hline - Luminosity & 52.048 & - Luminosity & 68.499 \\
\hline - Red & 75.284 & - Red & 68.208 \\
\hline - Green & 74.339 & - Green & 69.054 \\
\hline - Blue & 75.065 & - Blue & 71.724 \\
\hline Median: & & Median: & \\
\hline - Luminosity & 131 & - Luminosity & 173 \\
\hline - Red & 135 & - Red & 174 \\
\hline - Green & 135 & - Green & 171 \\
\hline - Blue & 136 & - Blue & 186 \\
\hline $\begin{array}{l}\text { Calibrated center of } \\
\text { mass: }\end{array}$ & & $\begin{array}{l}\text { Calibrated } \\
\text { center of mass: }\end{array}$ & \\
\hline$-\mathbf{x}$ & $0.889 \mathrm{in}$ & $-\mathbf{x}$ & 0.213 in \\
\hline$-\mathbf{y}$ & 0.889 in & $-\mathbf{y}$ & 0.213 in \\
\hline $\begin{array}{l}\text { Calibrated } \\
\text { perimeter: }\end{array}$ & $7.111 \mathrm{in}$ & $\begin{array}{l}\text { Calibrated } \\
\text { perimeter: }\end{array}$ & 1.707 in \\
\hline $\begin{array}{l}\text { Calibrated feret } \\
\text { diameter: }\end{array}$ & 2.006 in & $\begin{array}{l}\text { Calibrated feret } \\
\text { diameter: }\end{array}$ & 0.481 in \\
\hline
\end{tabular}

Number of statistical measurements applied to six different images before and after the suggested system implemented to show the difference between them, as tables (4) for image1, also the measurements of the other images can be shown in appendix(1):

\section{CONCLUSIONS}

1. The mixing of the symmetric and asymmetric encryption methods strength the proposed system.

2. The suggested key generator produced long maximum length period sequence, which provides a strong encryption method for images.

3. Increasing the structure complexity of the suggested key generator strength the cipher complexity.

4. Encryption of each byte of true image with different byte of cipher sequence making image more secure.

5. This system is more flexible for any type of images and for any size.

6 . The using of the long text increasing the complexity system.

\section{REFERENCES}

[1] P.Shanmugam \& C.Loganathan," Involuntary matrix in visual cryptography ", IJRRAS 6 (4), March 2011.

[2] Varsha Bhatt, "Implementation of new advanced image encryption algorithm to enhance security of multimedia component ",IJATER, ISSN No: 2250-3536, Volume 2, Issue 4, July 2012.

[3] Fauzan Saeed and Mustafa Rashid, "Integrating Classical Encryption with Modern Technique" IJCSNS International Journal of Computer Science and Network Security, VOL.10 No.5, May 2010.

[4] Kahate A., "Cryptography and network security", Tata-McGraw-Hill, $2^{\text {nd }}$ edition, 2008.

[5] Mohammed Abbas Fadhil Al-Husainy, "A Novel Encryption Method for Image Security", International Journal of Security and Its Applications, Vol. 6, No. 1, January, 2012. 
[6] Nada Abdul Aziz Mustafa," Design and Implementation proposed Encoding and Hiding Text in an Image", University of Sulaimani, M.Sc. Thesis, 2010.

[7] Mohammad Ahmad A. Alia," A New Approach to Public-Key Cryptosystem based on Mandelbrot and Julia Fractal sets", University Sains Malaysia, 2008.

[8] Mohammad Ahmad Alia and Azman Bin Samsudin," A New Digital Signature Scheme Based on Mandelbrot and Julia Fractal Sets", American Journal of Applied Sciences 4 (11): 848-856, 2007.

[9] Fadhil Salman Abed, "A proposed encoding and hiding text in an image by using fractal image compression", IJCSE, Vol. 4 No. 01 January 2012.

Appendix (1)

The experiments of statistical measurements for other images types can display the tables (5-9):

Table (5) Show the statistical measurements for encrypted image2 and original image2

\begin{tabular}{|c|c|c|c|}
\hline measurements & encrypted image1 & measurements & original image1 \\
\hline Calibrated area: & 3.160 sq. in & Calibrated area: & 1.778 sq. in \\
\hline Mean: & & Mean: & \\
\hline - Luminosity & 125.394 & - Luminosity & 104.017 \\
\hline - Red & 126.621 & - Red & 111.105 \\
\hline - Green & 126.027 & - Green & 103.7 \\
\hline - Blue & 123.127 & - Blue & 90.754 \\
\hline Standard deviation: & & $\begin{array}{l}\text { Standard } \\
\text { deviation: }\end{array}$ & \\
\hline - Luminosity & 50.926 & - Luminosity & 50.891 \\
\hline - Red & 73.843 & - Red & 59.854 \\
\hline - Green & 73.132 & - Green & 50.933 \\
\hline - Blue & 74.001 & - Blue & 49.882 \\
\hline Median: & & Median: & \\
\hline - Luminosity & 124 & - Luminosity & 110 \\
\hline - Red & 126 & - Red & 117 \\
\hline - Green & 125 & - Green & 111 \\
\hline - Blue & 119 & - Blue & 96 \\
\hline $\begin{array}{l}\text { Calibrated center of } \\
\text { mass: }\end{array}$ & & $\begin{array}{l}\text { Calibrated } \\
\text { center of mass: }\end{array}$ & \\
\hline$-\mathbf{x}$ & 0.889 in & $-x$ & 0.667 in \\
\hline$-\mathbf{y}$ & 0.889 in & $-\mathbf{y}$ & 0.667 in \\
\hline Calibrated perimeter: & 7.111 in & $\begin{array}{l}\text { Calibrated } \\
\text { perimeter: }\end{array}$ & 5.333 in \\
\hline $\begin{array}{l}\text { Calibrated feret } \\
\text { diameter: }\end{array}$ & 2.006 in & $\begin{array}{l}\text { Calibrated feret } \\
\text { diameter: }\end{array}$ & 1.504 in \\
\hline
\end{tabular}

Table (6) show the statistical measurements for encrypted image 3 and original image 3

\begin{tabular}{|l|c|l|c|}
\hline measurements & encrypted image3 & measurements & original image3 \\
\hline Calibrated area: & 3.160 sq. in & Calibrated area: & 1.778 sq. in \\
\hline Mean: & & Mean: & \\
\hline - Luminosity & 127.027 & - Luminosity & 116.318 \\
\hline - Red & 126.734 & - Red & 111.849 \\
\hline - Green & 127.481 & - Green & 116.879 \\
\hline - Blue & 129.876 & - Blue & 130.377 \\
\hline Standard deviation: & & $\begin{array}{l}\text { Standard } \\
\text { deviation: }\end{array}$ & \\
\hline - Luminosity & 51.644 & - Luminosity & 62.905 \\
\hline - Red & 74.021 & - Red & 58.378 \\
\hline
\end{tabular}




\begin{tabular}{|l|c|l|c|}
\hline- Green & 74.25 & - Green & $\mathbf{6 2 . 4 7 2}$ \\
\hline - Blue & 75.949 & - Blue & 83.148 \\
\hline Median: & & Median: & \\
\hline - Luminosity & 126 & - Luminosity & 124 \\
\hline - Red & 128 & - Red & 117 \\
\hline - Green & 129 & - Green & 125 \\
\hline - Blue & 132 & - Blue & 146 \\
\hline $\begin{array}{l}\text { Calibrated center of } \\
\text { mass: }\end{array}$ & & $\begin{array}{l}\text { Calibrated } \\
\text { center of mass: }\end{array}$ & \\
\hline - x & 0.889 in & - x & 0.667 in \\
\hline - y & 0.889 in & - y & 0.667 in \\
\hline Calibrated perimeter: & 7.111 in & $\begin{array}{l}\text { Calibrated } \\
\text { perimeter: }\end{array}$ & 5.333 in \\
\hline $\begin{array}{l}\text { Calibrated feret } \\
\text { diameter: }\end{array}$ & 2.006 in & $\begin{array}{l}\text { Calibrated feret } \\
\text { diameter: }\end{array}$ & 1.504 in \\
\hline
\end{tabular}

Table (7) show the statistical measurements for encrypted image4 and original image4

\begin{tabular}{|c|c|c|c|}
\hline measurements & encrypted image4 & measurements & original image 4 \\
\hline Calibrated area: & 3.160 sq. in & Calibrated area: & 0.046 sq. in \\
\hline Mean: & & Mean: & \\
\hline - Luminosity & 124.422 & - Luminosity & 96.259 \\
\hline - Red & 124.1 & - Red & 93.911 \\
\hline - Green & 125.697 & - Green & 98.884 \\
\hline - Blue & 122.93 & - Blue & 93.181 \\
\hline Standard deviation: & & $\begin{array}{l}\text { Standard } \\
\text { deviation: }\end{array}$ & \\
\hline - Luminosity & 52.254 & - Luminosity & 63.175 \\
\hline - Red & 75.602 & - Red & 73.756 \\
\hline - Green & 74.884 & - Green & 62.421 \\
\hline - Blue & 73.922 & - Blue & 57.943 \\
\hline Median: & & Median: & \\
\hline - Luminosity & 123 & - Luminosity & 80 \\
\hline - Red & 122 & - Red & 70 \\
\hline - Green & 124 & - Green & 89 \\
\hline - Blue & 119 & - Blue & 76 \\
\hline $\begin{array}{l}\text { Calibrated center of } \\
\text { mass: }\end{array}$ & & $\begin{array}{l}\text { Calibrated } \\
\text { center of mass: }\end{array}$ & \\
\hline$-\mathrm{x}$ & 0.889 in & $-\mathbf{x}$ & 0.107 in \\
\hline$-\mathbf{y}$ & 0.889 in & $-\mathbf{y}$ & 0.107 in \\
\hline Calibrated perimeter: & 7.111 in & $\begin{array}{l}\text { Calibrated } \\
\text { perimeter: }\end{array}$ & 0.853 in \\
\hline $\begin{array}{l}\text { Calibrated feret } \\
\text { diameter: }\end{array}$ & 2.006 in & $\begin{array}{l}\text { Calibrated feret } \\
\text { diameter: }\end{array}$ & 0.241 in \\
\hline
\end{tabular}

Table (8) show the statistical measurements for encrypted image 5 and original image 5 


\begin{tabular}{|c|c|c|c|}
\hline measurements & encrypted omage 5 & measurements & original image5 \\
\hline Calibrated area: & 3.160 sq. in & Calibrated area: & 1.778 sq. in \\
\hline Mean: & & Mean: & \\
\hline - Luminosity & 118.378 & - Luminosity & 60.214 \\
\hline- Red & 118.308 & - Red & $\mathbf{5 9 . 5 5 7}$ \\
\hline - Green & 118.814 & - Green & 59 \\
\hline - Blue & 120.664 & - Blue & 73.69 \\
\hline Standard deviation: & & $\begin{array}{l}\text { Standard } \\
\text { deviation: }\end{array}$ & \\
\hline - Luminosity & 52.951 & - Luminosity & 50.396 \\
\hline - Red & 75.964 & - Red & 59.607 \\
\hline - Green & 76.05 & - Green & 48.133 \\
\hline - Blue & 74.619 & - Blue & 47.285 \\
\hline Median: & & Median: & \\
\hline - Luminosity & 115 & - Luminosity & 50 \\
\hline- Red & 112 & - Red & 42 \\
\hline - Green & 113 & - Green & 49 \\
\hline - Blue & 114 & - Blue & 75 \\
\hline $\begin{array}{l}\text { Calibrated center of } \\
\text { mass: }\end{array}$ & & $\begin{array}{l}\text { Calibrated } \\
\text { center of mass: }\end{array}$ & \\
\hline$-\mathbf{x}$ & 0.889 in & $-\mathbf{x}$ & 0.667 in \\
\hline$-\mathbf{y}$ & 0.889 in & $-\mathbf{y}$ & 0.667 in \\
\hline Calibrated perimeter: & 7.111 in & $\begin{array}{l}\text { Calibrated } \\
\text { perimeter: }\end{array}$ & 5.333 in \\
\hline $\begin{array}{l}\text { Calibrated feret } \\
\text { diameter: }\end{array}$ & 2.006 in & $\begin{array}{l}\text { Calibrated feret } \\
\text { diameter: }\end{array}$ & 1.504 in \\
\hline
\end{tabular}

Table (9) show the statistical measurements for encrypted image6 and original image6

\begin{tabular}{|c|c|c|c|}
\hline measurements & encrypted image6 & measurements & original image6 \\
\hline Calibrated area: & 3.160 sq. in & Calibrated area: & 1.778 sq. in \\
\hline Mean: & & Mean: & \\
\hline - Luminosity & 133.588 & - Luminosity & 154.06 \\
\hline - Red & 132.911 & - Red & 150.454 \\
\hline - Green & 134.847 & - Green & 158.561 \\
\hline - Blue & 133.195 & - Blue & 144.416 \\
\hline Standard deviation: & & $\begin{array}{l}\text { Standard } \\
\text { deviation: }\end{array}$ & \\
\hline - Luminosity & 52.022 & - Luminosity & 69.083 \\
\hline - Red & 74.75 & - Red & 68.999 \\
\hline - Green & 74.471 & - Green & 66.806 \\
\hline - Blue & 76.678 & - Blue & 86.157 \\
\hline Median: & & Median: & \\
\hline - Luminosity & 134 & - Luminosity & 177 \\
\hline - Red & 134 & - Red & 169 \\
\hline - Green & 138 & - Green & 181 \\
\hline - Blue & 134 & - Blue & 178 \\
\hline $\begin{array}{l}\text { Calibrated center of } \\
\text { mass: }\end{array}$ & & $\begin{array}{l}\text { Calibrated center } \\
\text { of mass: }\end{array}$ & \\
\hline$-\mathbf{x}$ & 0.889 in & $-\mathbf{x}$ & 0.667 in \\
\hline
\end{tabular}


Design and implementation proposed system for encryption true images

\begin{tabular}{|l|c|l|c|}
\hline$-\mathrm{y}$ & $\mathbf{0 . 8 8 9}$ in & $-\mathrm{y}$ & $\mathbf{0 . 6 6 7}$ in \\
\hline Calibrated perimeter: & 7.111 in & $\begin{array}{l}\text { Calibrated } \\
\text { perimeter: }\end{array}$ & 5.333 in \\
\hline $\begin{array}{l}\text { Calibrated feret } \\
\text { diameter: }\end{array}$ & 2.006 in & $\begin{array}{l}\text { Calibrated feret } \\
\text { diameter: }\end{array}$ & 1.504 in \\
\hline
\end{tabular}

